\title{
AVALIAÇÃO DA QUALIDADE HIGIÊNICO-SANITÁRIA E MICROBIOLÓGICA DO PERNIL SUÍNO IN NATURA COMERCIALIZADO NO RIO DE JANEIRO.
}

\section{EVALUATION OF THE HYGIENIC-SANITARY AND MICROBIOLOGICAL QUALITY OF THE PORK LEG IN NATURA COMMERCIALIZED IN RIO DE JANEIRO}

\author{
Luana de Carvalho ${ }^{1}$ \\ Médica Veterinária - Universidade Castelo Branco - Av. Brasil, 9727 - Penha, Rio de \\ Janeiro - RJ, CEP 21.012-351. \\ https://orcid.org/0000-0002-3907-845X \\ luanamedvet23@gmail.com
}

\section{Andréa Matta Ristow ${ }^{2}$}

Mestre em Medicina Veterinária e Docente - Universidade Castelo Branco - Av. Brasil, 9727 - Penha, Rio de Janeiro - RJ, CEP 21.012-351.

https://orcid.org/0000-0002-8681-7200

andrearistow@globo.com

Túlio José de Freitas Goes ${ }^{3}$

Médico Veterinário, Mestre em Genética e Melhoramento Animal e Docente - Universidade Castelo Branco - Av. Brasil, 9727 - Penha, Rio de Janeiro - RJ, CEP 21.012-351.

\section{https://orcid.org/0000-0001-7753-2580}

tuliogoes_6@hotmail.com

\section{Christianne Perali ${ }^{4}$}

Doutora em Ciência, Tecnologia e Inovação em Agropecuária e Docente - Universidade Castelo Branco - Av. Brasil, 9727 - Penha, Rio de Janeiro - RJ, CEP 21.012-351 e Docente

- Faculdade de Ciências Agro-Ambientais - Rio de Janeiro - RJ, CEP 21.021-130.

$$
\frac{\text { https://orcid.org/0000-0002-4733-3828 }}{\text { chperali@terra.com.br }}
$$

1Participação ativamente da discussão dos resultados, Escrita - Primeira Redação, Investigação e Metodologia;

2Participação ativamente da discussão dos resultados, Administração do Projeto, Análise Formal, Conceituação, Escrita - Revisão e Edição, Investigação e Metodologia, Supervisão, Validação e Visualização;

${ }^{3}$ Participação ativamente da discussão dos resultados, Curadoria de Dados;

${ }^{4}$ Revisão e aprovação da versão final do trabalho, Escrita - Revisão e Edição, Supervisão, Validação e Visualização.

\section{RESUMO}

O presente estudo teve por objetivo avaliar e comparar a qualidade microbiológica da carne suína in natura comercializada em feiras livres e estabelecimentos comerciais do Rio de Janeiro, bem como, verificar as condições higiênico-sanitárias dos locais de comercialização. Foram coletadas 20 amostras de pernil suíno in natura comercializados em 20 diferentes feiras 
livres no estado do Rio de Janeiro e 20 amostras de Pernil suíno in natura comercializados, resfriados e adquiridos em 20 estabelecimentos comerciais do Rio de Janeiro. Após obtenção, as amostras foram encaminhadas para o Laboratório de Controle Microbiológico de Alimentos da Universidade Castelo Branco (UCB), para realização das análises microbiológicas. De acordo com os resultados das avaliações higiênico-sanitárias dos locais onde as amostras de pernil suíno in natura foram obtidas, observou-se uma média de $57,60 \%$ e $13,64 \%$ de não conformidade nas feiras livres e nos estabelecimentos comerciais, respectivamente. A presença de Salmonella sp. foi verificada em 14 (70\%) e 17 (85\%) amostras de pernil suíno in natura coletadas em feiras livres e estabelecimentos comerciais, respectivamente, estando estas amostras em não conformidade com a legislação vigente, sendo consideradas impróprias para o consumo. A análise dos resultados sugere que a qualidade microbiológica do pernil suíno in natura comercializado em feiras livres e estabelecimentos varejistas não atende às exigências da legislação que regulamenta esse setor.

Palavras-chave: Carne suína. Condições higiênico-sanitária. Salmonella sp.

\section{ABSTRACT}

The present study aimed to evaluate and compare microbiological quality of pork meat sell in street markets and in commercial establishments in Rio de Janeiro state, the hygienic-sanitary conditions of those places were also evaluated. It were collected 40 samples of fresh pork meat, 20 samples from street market and 20 samples from commercial establishments in Rio de Janeiro State. The samples were transported refrigerated to the Laboratory of Microbiological Control of Food of the Castelo Branco University for analyzing. The results showed an average of $57.60 \%$ and $13.64 \%$ of nonconformity respectively for the street market and for commercial establishments. The presence of Salmonella sp. was verified in $14(70 \%)$ of the samples collected in the street markets and 17 (85\%) for those collected in the commercial establishments, and so were not in compliance with the current legislation and were considered unfit for human consumption. The results suggests that the microbiological quality of pork leg meat marketed in both streets markets or commercial establishments in Rio de Janeiro State are not in compliance with Brazilian applicable laws requirements.

Keywords: Pork meat. Hygienic- sanitary conditions. Salmonella sp.

\section{INTRODUÇÃO}

\section{De acordo com a Associação} Brasileira de Proteína Animal (2020), a produção de carne suína no Brasil em 2018 foi de 3974 mil toneladas, sendo o consumo per capita nacional no mesmo ano de $15,9 \mathrm{~kg} / \mathrm{habitante}$.

A carne suína é a mais consumida mundialmente, seu valor nutricional está relacionado principalmente pela presença de proteínas de alto valor biológico, ácidos graxos monoinsaturados, vitaminas do complexo B, ferro, selênio e potássio. Contudo, no Brasil, esse padrão de consumo não é observado. Entre os três tipos cárneos, a maior demanda é pela carne bovina (MAGNONI; PIMENTEL, 2007; MARÇAL et al, 2016).

Diferentes autores relatam que as principais restrições ao incremento do consumo da carne suína no Brasil são os preconceitos com relação ao impacto sobre a saúde do consumidor, cortes volumosos, além da apresentação inadequada nos pontos de venda 
(ANTONANGELO et al, 2011; MARÇAL et al, 2016; SOUZA et al, 2016).

A carne, por ser um alimento de fácil deterioração, necessita que a sua conservação e comercialização sejam realizadas de forma adequada e de acordo com as legislações vigentes (LUNDGREN et al, 2009). No Brasil, a Resolução de Diretoria Colegiada - RDC $n^{\circ} 216$ (BRASIL, 2004) da Agência Nacional de Vigilância Sanitária - ANVISA estabelece os procedimentos de Boas Práticas para Serviços de Alimentação com o objetivo de promover a melhoria das condições higiênico-sanitárias desses estabelecimentos.

Atualmente, observa-se um aumento do número de pessoas que frequentam comércios populares, na intenção de obter produtos com valor reduzido e de boa qualidade. Dentre vários setores, os que mais se destacam, são as feiras livres e os mercados públicos (PEREIRA; SILVA; VIEIRA, 2016).

As feiras livres são muito conhecidas e frequentadas na cultura brasileira. Nestas, a comercialização dos alimentos, em geral, é feita de forma varejista, principalmente por ser uma forma de comércio móvel. Todavia, frequentemente são observadas muitas falhas no que tange à manipulação higiênico-sanitária desses alimentos, motivo de preocupação dos consumidores e dos serviços de fiscalização devido ao risco da ocorrência das Doenças Transmitidas por Alimentos DTA (ALMEIDA et al, 2011; LUNDGREN et al, 2009).

O objetivo do presente estudo foi avaliar e comparar a qualidade microbiológica da carne suína in natura comercializada em feiras livres e estabelecimentos comerciais do Rio de Janeiro, bem como verificar as condições higiênico-sanitárias dos locais de comercialização.

\section{MATERIAIS E MÉTODOS}

Durante o período de março a maio de 2018 , foram coletadas 20 amostras de pernil suíno in natura comercializadas em 20 diferentes feiras livres e 20 amostras de pernil suíno in natura comercializada resfriada adquiridas em 20 diferentes estabelecimentos comerciais. As amostras foram obtidas das quatro zonas (Norte, Central, Sul e Oeste) do município do Rio de Janeiro e de sete municípios (Magé, Duque de Caxias, São João de Meriti, Belford Roxo, Nova Iguaçu, Niterói e São Gonçalo) do estado do Rio de Janeiro. A obtenção das amostras foi realizada sem qualquer restrição quanto às condições higiênico-sanitárias do manipulador e do local de comercialização, visando com isso retratar a exata qualidade do local onde esta era comercializada.

No momento da coleta foram avaliadas, através de inspeção visual, as 
condições higiênico-sanitárias do local de comercialização. Para tanto, foram elaborados dois roteiros de inspeção, um para feira livre e o outro para os estabelecimentos comerciais, com base na RDC $n^{\circ} 216$ (BRASIL, 2004), sendo os dados obtidos registrados.

Os resultados médios das não conformidades verificadas nas avaliações das condições higiênico-sanitárias das feiras livres e dos estabelecimentos comerciais foram tratados estatisticamente pela análise de variância (ANOVA).

Em cada feira e estabelecimento comercial foi obtida uma amostra com aproximadamente $500 \mathrm{~g}$ de pernil suíno in natura. As amostras adquiridas foram acondicionadas pelo próprio comerciante e/ou pelo estabelecimento comercial. Após obtenção, foram imediatamente identificadas e transportadas resfriadas, em caixas isotérmicas, para o Laboratório de Controle Microbiológico de Alimentos da Universidade Castelo Branco (UCB) para realização das análises microbiológicas.

No laboratório, amostras de $25 \mathrm{~g}$ de cada amostra foram assepticamente pesadas e homogeneizadas em $225 \mathrm{~mL}$ de solução salina peptonada $0,1 \%$ estéril, obtendo-se a diluição $10^{-1}$. Em seguida, foram preparadas as demais diluições seriadas $\left(10^{-2}\right.$ até $\left.10^{-4}\right)$. Após, as amostras diluídas foram submetidas às seguintes análises microbiológicas: contagem de Bactérias Heterotróficas Aeróbias
Mesófilas e Psicrotróficas; identificação e contagem de Staphylococcus coagulase positiva; determinação do Número Mais Provável (NMP) de Coliformes a $45^{\circ} \mathrm{C}$ e Escherichia coli; e pesquisa de Salmonella $\mathrm{sp}$. Todas as análises foram realizadas de acordo com a metodologia descrita pela Instrução Normativa $n^{\circ} 62$ do Ministério da Agricultura Pecuária e Abastecimento MAPA (BRASIL, 2003).

O resultado da pesquisa de Salmonella sp. foi submetido ao Teste de Fisher para avaliar a influência do local da coleta.

\section{RESULTADOS E DISCUSSÃO}

As amostras de pernil suíno in natura foram obtidas de 20 diferentes locais do Rio de Janeiro. Embora, de acordo com Pereira; Silva; Vieira (2016), uma das vantagens da aquisição de produtos nas feiras livres seja o menor custo, no presente estudo foi verificado um preço médio para o quilo do pernil suíno in natura de $R \$ 13,10$ e $R \$ 12,15$ nas feiras e nos estabelecimentos comerciais, respectivamente.

De acordo com os resultados das avaliações higiênico-sanitárias dos locais onde as amostras de pernil suíno in natura foram obtidas, observou-se uma média de $57,60 \%$ e $13,64 \%$ de não conformidades nas feiras livres e nos estabelecimentos comerciais respectivamente. O resultado 
estatístico

Tabela 1 - Percentual de não conformidades verificadas nos estabelecimentos comerciais e nas feiras livres que comercializam Pernil suíno in natura no Rio de Janeiro:

\begin{tabular}{lcc}
\hline \multicolumn{1}{c}{ Não Conformidade } & Feira livre (\%) & $\begin{array}{c}\text { Estabelecimento comercial } \\
(\%)\end{array}$ \\
\hline $\begin{array}{l}\text { Ausência de abastecimento de } \\
\text { água }\end{array}$ & 95 & 0 \\
$\begin{array}{l}\text { Presença de animais e focos de } \\
\text { contaminação }\end{array}$ & 65 & 0 \\
$\begin{array}{l}\text { Presença de vetores e pragas } \\
\text { urbanas }\end{array}$ & 90 & 5
\end{tabular}

Fonte: Próprio autor.

Santos et al (2013), ao avaliarem as condições higiênico-sanitárias da feira livre da Colônia de Pescadores de Uruçuí / PI, também relatam a inexistência de abastecimento de água e de coletores de lixo, e atribuíram a estes a responsabilidade por não permitir a higienização do local, dos utensílios e dos manipuladores; e pela presença de insetos e roedores, respectivamente.

Tabela 2 - Percentual de não conformidades verificadas na conservação/comercialização do Pernil suíno in natura comercializado em estabelecimentos comerciais e nas feiras livres do Rio de Janeiro.

\begin{tabular}{ccc}
\hline Não Conformidade & Feira livre (\%) & Estabelecimento comercial (\%) \\
\hline Ausência de equipamento de refrigeração & 45 & 0 \\
Acondicionamento de forma incorreta & 95 & 35 \\
Exposição inadequada & 95 & 35 \\
Ganchos em estado de conservação & 70 & 20 \\
$\begin{array}{c}\text { insatisfatório } \\
\text { Ausência do carimbo do Serviço de } \\
\text { Inspeção }\end{array}$ & 85 & 5 \\
\hline
\end{tabular}

Fonte: Próprio autor.

Em 11 (55\%) feiras foi constatada a utilização de equipamento de refrigeração para conservação da carne. Nos locais onde havia a presença de equipamento de refrigeração, foi visualizada a presença de câmaras frias instaladas nos veículos dos 
feirantes, porém, para o funcionamento destas câmaras seria necessário que o veículo permanecesse ligado; este fato não foi observado. Em uma das feiras visitadas, observou-se a instalação da câmara no veículo do feirante, mas a manutenção da temperatura era feita através de gelo. Possivelmente, devido à refrigeração inadequada, $85 \%$ das amostras apresentavam-se com tonalidade vermelha escura e com odor fétido (50\%).

Nos estabelecimentos comerciais, a comercialização do pernil suíno in natura resfriado era realizada em balcão de refrigeração (55\%) e em gôndolas (45\%). Em relação às condições higiênicas destes equipamentos, $45 \%$ foram avaliadas como ótimas, $15 \%$ boas e $40 \%$ regulares. Apesar das amostras serem comercializadas sob refrigeração, $60 \%$ destas apresentaram coloração vermelha escura.

Lundgren et al (2009), ao avaliarem as condições higiênico-sanitárias da comercialização da carne bovina in natura em feiras livres e mercados públicos de João Pessoa / PB, também verificaram em $70,2 \%$ dos locais analisados a presença de refrigerador para conservação dos produtos, porém, de acordo com os autores, o ciclo do frio era interrompido, tendo em vista que os comerciantes retiravam as carnes para venda e as deixavam expostas aos compradores à temperatura ambiente durante todo o período de sua comercialização. Este fato também foi observado no presente estudo, onde $20 \%$ dos pernis suínos, comercializados nas feiras livres, estavam expostos ao sol.

O não acondicionamento de forma apropriada à exposição para venda foi verificada em $95 \%$ das feiras livres, onde os pernis suínos eram expostos em ganchos (95\%) sem nenhum tipo de proteção. Além disso, apenas 30\% dos ganchos se encontravam em bom estado de conservação e limpeza. Estes fatos podem ter contribuído para a proliferação de microrganismos levando à deterioração das carnes.

Além da falta de proteção, foi observado que somente $15 \%$ dos pernis suínos comercializados nas feiras livres apresentavam carimbo do Serviço de Inspeção. Em $10 \%$ das feiras foi constatado que a carne comercializada era oriunda de animais abatidos pelo próprio comerciante.

Diniz et al (2013) também verificaram a ausência do carimbo do Serviço de Inspeção com objetivo de avaliar as condições higiênico-sanitárias das carnes comercializadas em feiras livres da microrregião de Garanhuns, agreste meridional de Pernambuco. Os autores relatam que $33 \%$ dos comerciantes abatiam os animais em casa, clandestinamente, principalmente suínos e aves e que estes eram transportados para a feira em carroças, reboques ou trator, 
além disso, todas eram mantidas expostas à temperatura ambiente durante todo o dia, expondo os consumidores a diversos riscos, principalmente a ocorrência das DTA.

Em sete (35\%) estabelecimentos comerciais, os pernis eram vendidos sem embalagem, sendo que em 5 (25\%) estavam pendurados em ganchos sobre a gôndola de carnes resfriadas; e em 2 (10\%) estavam dispostos em bandejas de inox, somente sob proteção do vidro do balcão.

Em 13 (65\%) os pernis eram comercializados envoltos em embalagens plásticas, acondicionados em gôndolas (45\%) e em balcão fechado (20\%).

No caso das carnes comercializadas em ganchos, as condições higiênicas destes foram avaliadas como: boa (5\%), regular (10\%), ruim (10\%) e péssima (10\%). Em 95\% dos estabelecimentos a carne apresentava o carimbo do Serviço de Inspeção.

A presença de bancada para comercialização foi verificada em 19 (95\%) feiras, sendo que, destas, 5 (26,3\%) eram de madeira.

Machado et al. (2013), ao avaliarem - perfil higiênico-sanitário dos estabelecimentos que comercializavam carnes e derivados em feiras livres do município de Inhumas/GO, relatam o uso da bancada de madeira em $86,67 \%$ dos estabelecimentos, percentual este superior ao verificado no presente estudo. Segundo os autores, o uso da madeira aumenta o risco de contaminação do alimento por microrganismos patogênicos.

Em relação à avaliação dos manipuladores de alimentos das feiras livres, observou-se que todos apresentavam as unhas cortadas, porém, $65 \%$ apresentavam unhas sujas e em 15\% as unhas estavam pintadas. A utilização de adornos foi observada em $60 \%$ dos manipuladores.

$\mathrm{Na}$ avaliação das mãos dos manipuladores dos estabelecimentos comerciais, $25 \%$ possuíam as unhas grandes, $25 \%$ apresentavam as unhas sujas; e a utilização de adornos foi visualizada em $10 \%$.

Em todas as feiras observou-se ausência de touca e 11 manipuladores (55\%) não utilizavam vestimenta adequada para a tarefa realizada. O uso de aventais foi verificado em oito manipuladores (40\%), porém, seis (40\%) apresentavam os aventais sujos e dois (25\%) usavam aventais de cor (vermelha e preta). 
Tabela 3 - Percentual de não conformidades verificadas na manipulação do Pernil suíno in natura comercializado em estabelecimentos comerciais e nas feiras livres do Rio de Janeiro

\begin{tabular}{ccc}
\hline Não Conformidade & Feira livre (\%) & Estabelecimento comercial (\%) \\
\hline Lesão nas mãos & 0 & 0 \\
Unhas grandes & 0 & 25 \\
Unhas pintadas & 15 & 0 \\
Unhas sujas & 65 & 25 \\
Utilização de adornos & 60 & 10 \\
Ausência de Touca & 100 & 5 \\
Ausência de Luva de malha de aço & 100 & 70 \\
Uniforme inadequado & 55 & 35 \\
Panos para secagem das mãos & 50 & 5 \\
Hábitos não higiênicos durante a & 55 & 25 \\
Alimentação no local de trabalho & 10 & 0 \\
Manipulação de dinheiro e alimento ao & 100 & 0 \\
Não higienização adequada das mãos & 100 & 30 \\
\hline
\end{tabular}

Fonte: Próprio autor.

Nos estabelecimentos comerciais, 17 (85\%) utilizam uniformes brancos e destes, 13 (65\%) eram limpos e quatro (20\%) sujos. Foi verificado que $3(15 \%)$ utilizavam aventais de cor (preta e amarela).

Nos estabelecimentos comerciais a não utilização de toucas e luvas de malha de aço foi verificada em um (5\%) e 14 $(70 \%)$ respectivamente.

Durante a coleta do material, também foi possível verificar que $50 \%$ dos manipuladores das feiras utilizavam panos para secagem das mãos; 55\% apresentaram hábitos não higiênicos durante a manipulação da carne, como: passar a mão no rosto, tossir e espirar. Também foi possível averiguar que 10\% dos manipuladores comiam no local de trabalho e $100 \%$ manipulavam alimentos e dinheiro ao mesmo tempo, bem como não realizavam a higienização adequada das mãos na troca das tarefas.

Nos estabelecimentos comerciais, 6 (30\%) manipuladores não realizaram a higiene das mãos durante a troca de tarefas. Também foi observado em 1 (5\%) estabelecimento, o uso de pano para secagem das mãos e em 5 (25\%) os manipuladores não evitavam passar a mão no rosto, tossir ou espirar durante a manipulação dos alimentos.

Falhas semelhantes aos verificados no presente estudo, foram relatados por Silva et al (2016) em seu estudo sobre as 
condições higiênico-sanitárias de carnes comercializadas em feiras livres do município de União dos Palmares Alagoas. De acordo com os autores, cerca de $45 \%$ dos manipuladores não usavam aventais apropriados para executar a atividade em questão, sendo observado também que $90 \%$ dos feirantes realizavam alguma refeição durante 0 trabalho. Aproximadamente $75 \%$ dos vendedores não se apresentavam limpos; e, além disso, todas as barracas observadas os vendedores manipulavam os alimentos e recebiam simultaneamente o pagamento das vendas. O uso de adornos como relógios, pulseiras, anéis entre outros era comum.

De acordo com a RDC $\mathrm{n}^{\circ} 12$ (BRASIL, 2001) da ANVISA, o padrão microbiológico para carne suína in natura resfriada ou congelada é ausência de Salmonella sp. em 25 gramas. A presença de Salmonella sp. foi verificada em 14 (70\%) e 17 (85\%) amostras de pernil suíno in natura coletadas em feiras livres e estabelecimentos comerciais, respectivamente, estando estas amostras em não conformidade com a legislação vigente, sendo consideradas impróprias para o consumo. A análise estatística demonstrou que não houve diferença significativa $(p=0,4506)$ entre os resultados obtidos.

Resultado semelhante ao do presente estudo foi descrito por Tessmann et al. (2008) que relataram uma contaminação por Salmonella sp. de $80 \%$ das amostras de carne suína in natura obtidas de feiras livres da cidade de Pelotas/RS.

No presente estudo, a procedência da carne não foi verificada em $85 \%$ das amostras oriundas das feiras livres; isso demonstra que pode ter havido falta de cuidado na sua manipulação durante o abate, transporte e comercialização, porém, 95\% das amostras obtidas de estabelecimentos comerciais apresentavam carimbo do Serviço de Inspeção Federal. Este resultado demonstra que podem ter ocorrido falhas nos cuidados higiênicos realizados durante - preparo da carcaça, além das observadas nos locais de comercialização.

Segundo Neitzke; Roza; Weber (2017), quanto maior o número de suínos portadores/excretores de Salmonella sp., maior será a dificuldade de controlar os pontos críticos durante o preparo da carcaça. Por esta razão, o número de animais portadores que chega ao abate tem sido apontado como primeiro ponto crítico de controle em relação a este microrganismo.

A RDC no 12 (BRASIL, 2001) não estabelece padrão microbiológico para Bactérias Heterotróficas Aeróbias Mesófilas (BHAM) e Psicrotróficas (BHAP); nem para coliformes ou Staphylococcus coagulase positiva, porém, estes grupos 
são conhecidos como microrganismos indicadores, ou seja, sua contagem permite avaliar as condições higiênicosanitárias nas quais 0 produto foi processado.

A contagem média de BHAM observado no presente trabalho foi de 1,98 $\pm 1,29 \times 10^{6} \mathrm{UFC} / \mathrm{g}$ para feira livre e de 2,11 $\pm 1,33 \times 10^{6} \mathrm{UFC} / \mathrm{g}$ para estabelecimentos comerciais.

Os resultados verificados para contagem de BHAP apresentaram valor médio de $1,39 \times 10^{6} \pm 1,34 \mathrm{UFC} / \mathrm{g}$ para feiras livres e $1,12 \times 10^{6} \pm 1,15$ UFC/g para estabelecimentos comerciais.

Silva (1995) afirma que a carne in natura contendo elevada contagem de microrganismos psicrotróficos $\left(10^{5}-10^{6}\right.$ UFC/g) apresenta graves riscos de estar deteriorada, além de ter suas características nutricionais e sensoriais comprometidas. No presente estudo, todas as amostras apresentaram contagens de BHAP maiores que $10^{6} \mathrm{UFC} / \mathrm{g}$, o que pode justificar a presença de coloração vermelha escura e odor fétido observados na maioria das amostras analisadas.

Em um estudo realizado na cidade de Alfenas/MG, Oliveira; Nascimento; Fiorini (2002) confirmaram contaminação em carnes suínas frescas e descreveram uma contagem de $4,0 \times 10^{2} \mathrm{UFC} / \mathrm{g}$ a $7,3 \times 10^{5}$ UFC/g, enquanto Martins et al. (2007), em um estudo realizado em feiras livres na microrregião do Brejo Paraibano, relataram uma contaminação por microrganismos psicrotróficos superior a $10^{5} \mathrm{UFC} / \mathrm{g}$ em 99\% das amostras avaliadas.

Em sete (35\%) amostras oriundas das feiras livres foi detectada a presença média de 28 NMP de Coliformes Termotolerantes/g, sendo todas positivas para E. coli. Nas amostras obtidas dos estabelecimentos comerciais, três (15\%) apresentaram a presença de Coliformes Termotolerantes, com contagem média de 4,07 NMP/g, porém, a presença de E. coli foi confirmada em apenas duas.

Resultados superiores foram descritos por Lundgren et al. (2009), em seu estudo, onde a presença de Coliformes Termotolerantes foi verificada em 100\% das amostras de carne in natura comercializadas em feiras livres e mercados públicos. Segundo os autores, em $60 \%$ foi confirmada a presença de $E$. coli.

A presença de $E$. coli indica a má qualidade higiênico-sanitária dos produtos, bem como a presença de outros microrganismos enteropatogênicos, como a Salmonella sp, como verificado no presente estudo.

No presente estudo, a presença de Staphylococcus coagulase positiva não foi verificada em $100 \%$ das amostras analisadas, apesar das não conformidades observadas na manipulação destes alimentos. Este resultado pode ser explicado pelo fato deste microrganismo 
ser um péssimo competidor, portanto, a alta contagem de Bactérias Heterotróficas Aeróbias Mesófilas e Psicrotróficas verificada no presente estudo pode ter inibido o seu crescimento.

\section{CONCLUSÃO}

Os resultados das análises microbiológicas indicaram que a carne suína in natura, comercializada no Rio de Janeiro, não estava em conformidade com a legislação vigente por apresentar Salmonella sp., representando um risco à saúde dos consumidores.

As elevadas contagens dos microrganismos indicadores e o resultado da avaliação visual, demonstraram condições higiênico-sanitárias insatisfatórias tornando imprescindível a implantação das Boas Práticas de Fabricação nos locais de comercialização, de forma a proporcionar um produto com qualidade e segurança ao consumidor.

\section{REFERÊNCIAS}

ALMEIDA, R. B.; DINIZ, W. J. S.; SILVA, P. T. V.; ANDRADE, L. P.; DINIZ, W. P. S.; LEAL, J. B. G.; BRANDESPIM, D. F. Condições higiênico-sanitárias da comercialização de carnes em feiras livres de Parantama, PE. Alimentos e Nutrição. v. 22, n. 4, p. 585 - 592, 2011. Disponível em: http://serv-

bib.fcfar.unesp.br/seer/index.php/alimento s/article/viewArticle/1717. Acesso em: 10 abr. 2018.

ANTONANGELO, A.; RUV, C.; DUTRA, J. B.; RIBEIRO, N. M.; DOLAZZA, R. M. Perfil de los consumidores de cerdo em el municipio de Botucatu - SP. Tékhne $\varepsilon$ Lógos, Botucatu, SP, v. 2, n. 2, fev. 2011. Disponível em: $<$ http://www.fatecbt.edu.br/seer/index.php/ tl/article/viewFile/101/60> Acesso em 23 fev. 2018.

ASSOCIAÇÃO BRASILEIRA DE PROTEÍNA ANIMAL - ABPA. Suinocultura - Resumo do setor de suínos. $O$ talento brasileiro para a suinocultura. Disponível em: <http://abpabr.com.br/setores/suinocultura/resumo>.

Acesso: 07 mar. 2020

BRASIL, Agência Nacional de vigilância Sanitária. Resolução de Diretoria Colegiada no 12, de 02 de Janeiro de 2001 aprova o Regulamento Técnico sobre Padrões Microbiológicos para Alimentos em conformidade com os Anexos desta Resolução. Diário Oficial da União, Brasília, 02 de janeiro de 2001. Disponível em:<http://portal.anvisa.gov.br/documents/ 33880/2568070/RDC_12_2001.pdf/15ffddf 
6-3767-4527-bfac-740a0400829b>Acesso

em: 14 abril. 2018

BRASIL. Ministério da Saúde. Agência Nacional de Vigilância Sanitária. Resolução de Diretoria Colegiada - RDC ํㅜ 216, de 15 de setembro de 2004. Dispõe sobre Regulamento Técnico de Boas Práticas para Serviços de Alimentação. Diário Oficial da União, Brasília, 15 de setembro de 2004. Disponível em: <http://portal.anvisa.gov.br/documents/339 16/388704/RESOLU\%25C3\%2587\%25C3 $\% 25830-$

RDC\%2BN\%2B216\%2BDE\%2B15\%2BD

E\%2BSETEMBRO\%2BDE\%2B2004.pdf/2 3701496-925d-4d4d-99aa-

9d479b316c4b>. Acesso em: 30 mar. 2018.

BRASIL. Ministério da Agricultura, Pecuária e Abastecimento. Instrução Normativa SDA № 62 de 26/08/2003. Dispõe sobre os métodos analíticos oficiais para análises microbiológicas para controle de produtos de origem animal e água. Diário Oficial da União, Brasília. 26 de agosto de 2003. Disponível em: $<$ https://www.legisweb.com.br/legislacao/? id=75773 >. Acesso em: 10 fev. 2018.

DINIZ, W. J. S.; ALMEIDA, R. B. de; LIMA, C. N. de; OLIVEIRA, R. R. de; QUIRINO, W. A.; BRANDESPIM, D. F. Aspectos higiênicos da comercialização de carnes em feiras livres: a percepção do comerciante. Acta Veterinaria Brasilica, v. 7, n. 4, p. 294 - 299. Brasília, 2013. Disponível em: $<$ https://periodicos.ufersa.edu.br/index.php /acta/article/viewFile/3431/5294>. Acesso em: 06 jan.2018.

LUNDGREN, P. U.; SILVA, J. A.; MACIEL, J. F.; FERNANDES, T. M. Perfil da qualidade higiênico-sanitária da carne bovina comercializada em feiras livres e mercados públicos de João Pessoa/PB Brasil. Alim. Nutr. v. 20, n. 1, p. $113-119$ 2009. Disponível em:<http://servbib.fcfar.unesp.br/seer/index.php/alimento s/article/viewFile/953/780>. Acesso em: 10 out. 2017.

MACHADO, S. S.; CONRADO, L. A.; SILVA, G. DA; BLANCO, A. J. V. Avaliação do perfil higiênico-sanitário dos estabelecimentos comerciais e manipuladores de carne e derivados em feiras livres. Inhumas, Porto, XIII Safety, Health and Environment World Congress, 2013. 5 p. Disponível em: <http://copec.eu/congresses/shewc2013/p roc/works/62.pdf>. Acesso em: 12 maio 2018.

MAGNONI, D.; PIMENTEL, I. A importância da carne suína na nutrição humana. São Paulo: UNIFEST. 2007. Disponível em: $<$ http://www.abcs.org.br/attachments/099_ 4.pdf> Acesso em 15 mar. 2018. 
MARÇAL,

D. A.; ABREU, R. C. de; CHEUNG, T. L.; KIEFER, C. Consumo da carne suína no Brasil: aspectos simbólicos como determinantes dos comportamentos.

Revista em Agronegócio e Meio Ambiente, Maringá/PR, v. 9, n. 4, p. 9891005, 2016. Disponível em: $<$ http://periodicos.unicesumar.edu.br/index .php/rama/article/view/3743/2862>.

Acesso: 19 mar. 2018.

MARTINS, T. D. D.; MOREIRA, R. T.; SILVA, L. DA P. G. DA; BATISTA, E. DE S.; SANTOS, R. J. C. DOS; SANTOS, J. G. DOS; PEREIRA, W. E.; SILVA, R. R. DA. Avaliação microbiológica da carne suína in natura, comercializada na microrregião do brejo paraibano. Revista Higiene Alimentar, São Paulo, v. 21, n. 153, p.7781, jul-ago/2007. Disponível em < https://repositorio.ufpb.br/jspui/bitstream/1 23456789/522/1/CMS11072014.pdf>.

Acesso em: 19 mar. 2018.

NEITZKE, D. C.; ROZA, C. R. da; WEBER, F. H.. Segurança dos alimentos: contaminação por Salmonella sp. no abate de suínos. Brazilian Journal of Food Technology, Campinas, v. 20, p.1-7, mar. 2017. Disponível em: <http://www.scielo.br/pdf/bjft/v20/19816723-bjft-20-e2015063.pdf>. Acesso em: 02 maio 2018.

OLIVEIRA, N. M. S; NASCIMENTO, L. C.; FIORINI, J. E. Isolamento e identificação de bactérias facultativas mesofílicas em carnes frescas bovinas e suínas. Higiene Alimentar, v. 16, n. 91, p. 68-74. 2002.

PEREIRA, W. A. de S.; SILVA, J. F. B. da; VIEIRA, P. P. F. Gestão da qualidade: aplicabilidade de Boas Práticas de Fabricação nas feiras livres e mercados públicos do munícipio de João Pessoa. Applied Tourism, João Pessoa, v. 1, n. 3, p.41-52, dez. 2016. Disponível em: $<$ https://siaiap32.univali.br/seer/index.php/i jth/article/view/10235/5764.> Acesso em: 25 maio 2018.

SANTOS, D. B.; MACHADO, M. S.; SAMPAIO, A. H. R.; VIEIRA, L. M. Avaliação das condições higiênicosanitárias da feira livre da colônia dos pescadores no município de Uruçuí- PI. Enciclopédia Biosfera, Goiânia, v. 9, n. 16, p.24-34, jul. 2013. Disponível em: $<$ http://www.conhecer.org.br/enciclop/201 3a/miltidisciplinar/AVALIACAO\%20DAS\% 20CONDICOES.pdf $>$. Acesso em: 17 abr. 2018.

SILVA, J. A. Extensão da vida de prateleira da carne bovina pela utilização de sanitizantes físicos e químicos. 1995. 141 f. Tese (Doutorado) Curso de Engenharia de Alimentos, Universidade Estadual de Campinas, Campinas, 1995. Disponível em: $<$ http://www.sebrae.com.br/sites/PortalSeb rae/artigos/conheca-os-avancos-na- 
producao-de-

suinos,abf4d15a9567d410VgnVCM10000

03b74010aRCRD>. Acesso em: 06 jan. 2018.

SILVA, J. V.; SILVA, Y. F.; BUENO, N. B.; MELO, I. S. V. Avaliação técnica das condições higiênico sanitárias de carnes comercializadas em feiras livres de um Município Alagoano. CONGRESSO NACIONAL DE PESQUISA E ENSINO EM CIÊNCIAS. Paraíba, Anais..., 2008. Disponível em: <http://www.editorarealize.com.br/revistas/ conapesc/trabalhos/TRABALHO_EV058 MD4_SA80_ID1161_12052016193009.pdf > Acesso em: 06 jan. 2018. (evento?)

SOUZA, C. C. de; GABRIEL, R.; NETO, J. F. dos R.; FRAINER, D. M. A percepção de compradores sobre a qualidade da carne suína in natura no mercado varejista de Campo Grande (MS). Extensão Rural, Campo Grande, v. 23, n. 3, set. 2016. Disponível em:<https://periodicos.ufsm.br/extensaoru $\mathrm{ral} /$ login?source=\%2Fextensaorural\%2Far ticle\%2Fview\%2F21488\%2Fpdf>. Acesso em: 16 abr. 2018.

TESSMANN, C.; ZOCCHE, F.; LIMA, A, S.; BASSANI, M.; LOPES, G, V.; SILVA, W, P. Ocorrência e perfil de sensibilidade a antibióticos de Salmonella spp. Isolada em cortes de carne suína comercializados em feiras-livres de Pelotas, RS. Boletim do

\section{Centro de Pesquisa de Processamento} de Alimentos. Curitiba v. 26, n. 2, p. $307-$ 313, jul./dez. $2008 . \quad$ DOl: 10.5380/cep.v26i2.13294. Disponível em: $<$ https://www.researchgate.net/publication/ 273406026_ocorrencia_e_perfil_de_sensi bilidade_a_antibioticos_de_salmonella_sp p_isolada_em_cortes_de_carne_suina_co mercializados_em_cortes_de_carne_suin a_comercializados_em_feiraslivres_de_pelotas_rs>. Acesso em: 29 abr. 2018. 